\title{
Speech articulation disorder in patient using removable orthodontic appliance
}

\author{
Dita Hofinessia*, Ervin Rizali", Elih** \\ "Department of Oral Biology, Faculty Of Dentistry Universitas Padjadjaran \\ "Department of Orthodontics, Faculty of Dentistry Universitas Padjadjaran
}

\begin{abstract}
Introduction: The physiologic of speech is a complex thing involving organ respiration, phonation, resonance, articulation and neurologic integration. The use of removable orthodontic appliance may cause speech articulation disorder and may affect patient's speech function. The purpose of this research was to obtain an illustration of speech articulation disorder in patient using removable orthodontic appliance. Methods: This research was a descriptive research using the one group pretest posttest design. Speech articulation disorder was determined by testing the labiodental, linguoalveolar and linguopalatal consonants using the Goldman-Fristoe Test of Articulation test equipment. Results: Research result indicated that there was speech articulation disorder in the pronunciation of the consonants $/ \mathrm{f} / ; / \mathrm{v} /$; $/ \mathrm{t} / ; / \mathrm{d} / ; / \mathrm{r} / ; / \mathrm{s} / ; / \mathrm{j} / ; / \mathrm{g} / ; / \mathrm{k} /$ in the beginning of the word as many as $37 \% ; 23 \% ; 30 \% ; 57 \% ; 77 \% ; 93 \%$; $50 \%$; $40 \%$; $23 \%$, in the middle of the word as many as $37 \% ; 27 \% ; 60 \% ; 60 \% ; 83 \% ; 97 \% ; 57 \% ; 50 \% ; 80 \%$ and in the end of the word as many as $17 \%$; - ; $27 \%$; $50 \% ; 83 \%$; $97 \%$; - ; ; $57 \%$ in the people using removable orthodontic appliance for the first time. Conclusion: Speech articulation disorders in patients with orthodontic removable appliance varies with the presentation of having most articulation disorders is in the pronunciation of consonants / $\mathrm{s} /$ in words.
\end{abstract}

Keywords: Speech Articulation disorder, removable orthodontic appliance.

\section{INTRODUCTION}

Humans are social beings who continue to communicate during their lives both orally and in writing. Communication is done by someone to reveal ideas and expressions using words through a process called speech. ${ }^{1}$

The physiologic of speech is a complex thing involving organ respiration, phonation, resonance, articulation and neurologic integration. According to some communication experts, speech is the ability of a person to communicate using a language that requires a harmonious combination of the neuromuscular system to secrete phonation and articulation of the voice. The phonation is performed by the larynx, while the articulation is performed by teeth, tongue, lips, alveolar bones, palate and soft palate. Bone, muscular, dental, or soft tissue abnormalities affecting the movement or work of these articulated organs can lead to speech disorder. ${ }^{2,3,4}$ Besides that, dental appliance (either orthodontic or prosthodontic appliances) can cause speech articulation disorders in the pronunciation of labiodental consonants, 
linguoalveolar and linguodental. ${ }^{5}$ Removable orthodontic appliance is a device that can be used and detached by the patient without the assistance of the operator. A removable orthodontic appliance generally consists of active components, retention components and acrylic base plate. ${ }^{6,7}$ The use of removable orthodontic appliance can affect the dimensions of oral cavities, thus altering the vocal tract that affects the clarity of one's speech. The removable orthodontic appliance is also known to cause the wearer to experience distortion in many consonant pronunciations and affect speech articulation. One of the causes is the use of acrylic as a base plate which is one of the anchoring component (Anchorage). The placement of acrylic can affect the position of the tongue and the shape of the palate, which is part of the articulation organ, causing the patient with limitations and difficulties when talking. 5,8-10 The purpose this study is to obtain data of speech articulation disorder in patients using orthodontic removable appliance.

\section{METHODS}

The research conducted is a descriptive study with the design of one group pretests posttest. The research population is patient who came to the Department of Orthodontic of Dental Hospital of Padjadjaran University (RSGM) in March-April 2012. The sample selection method is by consecutive sampling that meets the sample criteria and fulfills a total sample of 30 , some of the considerations used are as following: Patients who use removable maxillary and mandibular orthodontic appliance for the first time, the thickness of the acrylic base plate on removable orthodontic appliance is not more than $3 \mathrm{~mm}$, has no prior articulation disorder, is registered as a patient in Dental Hospital of Padjadjaran University (RSGM), willing to be research samples and sign informed consent, as well as cooperative.

The tools and materials used in this research are the modified speech articulation test tools Goldman-Fristoe Test of Articulation, informed consent, articulation examination datasheet, and sound recording equipment. First attempt, conduct speech articulation test before the research sample use the maxillary and mandibular removable orthodontic appliance, the research sample is requested to pronounce the consonant word with labiodental consonants/f/, $/ \mathrm{v} /$, linguoalveolar $/ \mathrm{t} /, / \mathrm{d} /, / \mathrm{n} /, / \mathrm{l} /, / \mathrm{r} /, / \mathrm{s} /$ and linguopalatal $/ \mathrm{j} /, / \mathrm{k} /, / \mathrm{g} /$ which is placed at the beginning, middle and end of the words by demonstrating a modified speech articulation test of Goldman-Fristoe Test of Articulation and is recorded by using a sound recording device. Then the results are recorded by providing scoring using code from 0-9 with the following criteria:

0 : Consonant pronunciation cannot be distinguished from normal pronunciation. 1 :Consonant pronunciation is clear, but after it is applied to a word, a distortion occurs. 2 :Consonant pronunciation is clear, but after it is applied to words, a certain consonant replacement or substitution occurs. 3 :Consonant pronunciation is clear, but after it is applied to words, certain consonants are not spoken or omitted. 4 : Consonant pronunciation is clear, but after it is applied to words, addition of a certain consonant occurs. 5 :Consonant pronunciation is unclear, but after it is applied to words, consonant pronunciation cannot be distinguished from normal pronunciation. 6 :Consonant pronunciation is unclear but after it is applied to a word, there is deviation or distortion. 7 :Consonant pronunciation is unclear, but after it is applied to words, certain consonant replacement or substitution occurs. 8 :Consonant pronunciation is unclear, but after being applied to words, certain consonants are not spoken or omitted. 9 :Pronunciation of consonants is unclear, but after being applied to words, addition of certain consonants occur After obtaining the code from the test, the code is then grouped based on the symptoms of speech articulation disorders:

1. Distortion : kode 1,5, atau 6. 2 . Substitution: kode 2 atau 7. 3. Omission: kode 3 atau 8. 4. Addition : kode 4 atau 9. If there is one of the symptoms above, then the sample is declared of experiencing speech articulation disorders. The results of the study are recorded on the articulation examination sheet.

The second attempt, the researchers asked the study sample to use maxillary and mandibular removable orthodontic appliance, then the study sample was asked to pronounce certain consonants words like the procedure that had been done previously. The results of the study are again recorded on the articulation examination sheet. 


\section{RESULTS}

This study was conducted on 30 patients as study samples. The results were obtained from the consonant pronunciation test of labiodental $/ \mathrm{v} /$, $/ \mathrm{f} /$, linguoalveolar $/ \mathrm{t} /, / \mathrm{d} /, / \mathrm{n} /, / \mathrm{l} /, / \mathrm{r} /, / \mathrm{s} /$ and linguopalatal $/ \mathrm{j} /, / \mathrm{g} /, / \mathrm{k} /$ by using modifies speech articulation test Goldman-Fristoe Test of Articulation. The picture of speech articulation disorder in patients wearing removable orthodontic appliance can be presented as in the diagram below:

Diagram 4.1 shows the presentation of the speech articulation disorder of consonant placement at the beginning of words from the highest to the lowest after the sample used removable orthodontic appliance.

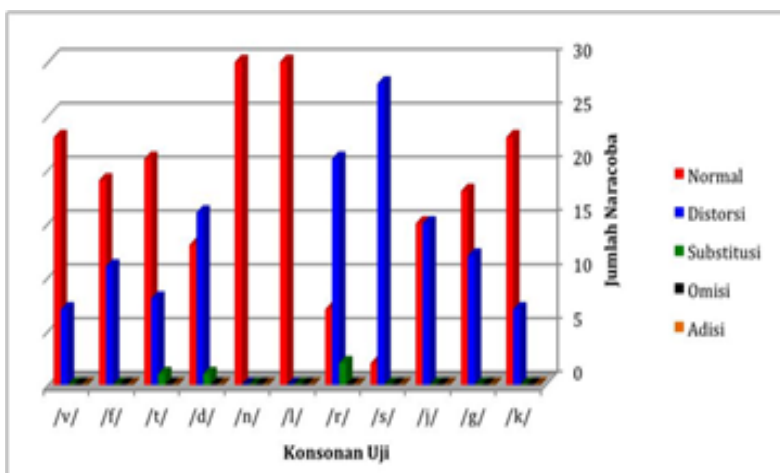

Figure 1. Distribution of Research Respondents After The Use of Orthodontic Removable Appliances, Based on Speech Articulation Disorders of Consonant Placement at the Beginning of Words in Labiodental, Linguoalveolar and Linguopalatal Consonant Pronunciation.

Consonant articulation disorders include / $\mathrm{s}$ / with the highest presentation of 28 people (93\%) having distortion, / $\mathrm{r} /$ as many as 21 people (70\%) had distortion and 2 people ( $7 \%$ ) had substitution, / d / as many as 16 people (54\%) had distortion and 1 person (3\%) had substitution, / $\mathrm{j} /$ as many as 15 people (50\%) had distortion, / g / as many as 12 people $(40 \%)$ had distortion, / $\mathrm{f} /$ as many as 11 people ( $37 \%$ ) had distortion, / $\mathrm{t} /$ as many as 8 people $(27 \%)$ had distortion and 1 person $(3 \%)$ had substitution, / k / and / v / as many as 7 people (23\%) had distortion.

While consonants / $\mathrm{n} /$ and / I / do not experience impaired speech articulation. Diagram 4.2 shows the presentation of speech articulation disorders with the placement of consonants in the middle of the words from the highest to the lowest after the respondents has used removable orthodontic appliances. Consonant articulation

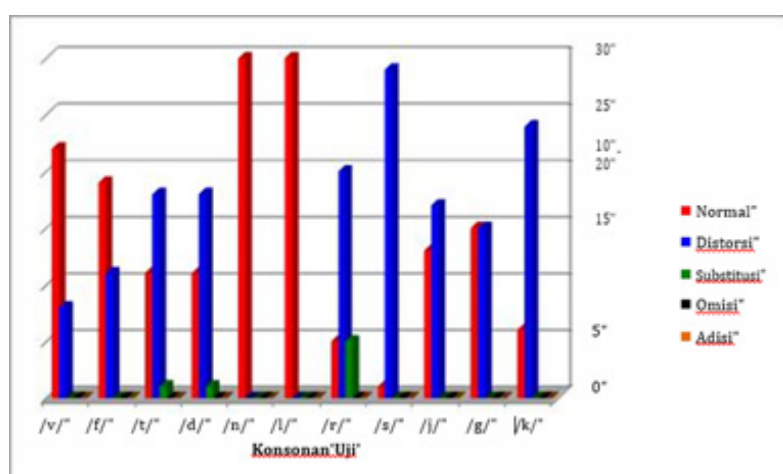

Figure 2. Distribution of Research Respondents After The Use of Removable Orthodontic Appliances, Based on Speech Articulation Disorders of Consonant Placement in the Middle of Words in Labiodental, Linguoalveolar and Linguopalatal Consonants.

disorders include / s / with the highest presentation of 29 people (97\%) had distortion, I $\mathrm{r} / \mathrm{as}$ many as 20 people $(66 \%)$ had distortion and 5 people (17\%) experiencing substitution, / $\mathrm{k} /$ as many as 24 people (80\%) had distortion, / $\mathrm{t} /$ and / d / as many as 18 people $(60 \%)$ had distortion, / j / as many as 17 people (57\%) had distortion, / $\mathrm{g} / \mathrm{as}$ many as 15 people $(50 \%)$ had distortion, / $\mathrm{f}$ / as many as 11 people (37\%) had distortion, and / $\mathrm{v} /$ as many as 8 people (27\%) had distortion. While consonants / $\mathrm{n} /$ and / I / do not experience impaired speech articulation.

Diagram 4.3 shows the presentation of the speech articulation disorders in the placement of consonants at the end of the word from the highest to the lowest after the respondents has used removable orthodontic appliance.

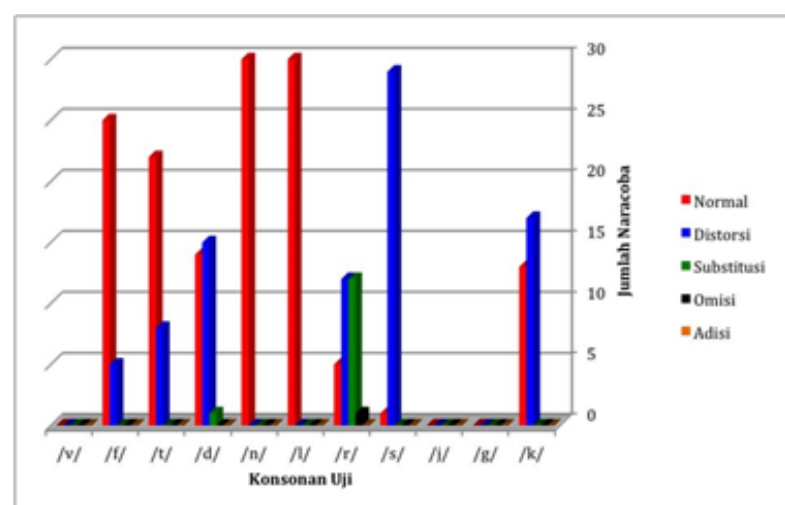

Figure 3. Distribution of Research Respondents After The Use of Removable Orthodontic Appliances, Based on Speech Articulation Disorders of Consonant Placement at the End of Words in Labiodental, Linguoalveolar and Linguopalatal Consonants. 
Consonant articulation disorders include / $\mathrm{s} /$ with the highest presentation of 29 people (97\%) had distortion, / r / as many as 12 people (40\%) had distortion, 12 people (40\%) experiencing substitution and 1 person (3\%) experienced omission, / k / as many as 17 people (57\%) had distortion, / $\mathrm{d} /$ as many as 15 people (50\%) had distortion, / t / as many as 8 people $(27 \%)$ had distortion, and / $f /$ as many as 5 people ( $17 \%)$ had distortion. While consonants / $\mathrm{n} /$ and / I / do not experience impaired speech articulation.

\section{DISCUSSION}

The consonant / s / is one of the linguoalveolar consonants formed with the tip touching the upper alveolar. The consonant / s / also known as the spirant consonant formed by the presence of air coming out of the lungs which is impeded in the area of contact between the articulation organs and at the same time a hissing sound is heard. The use of removable orthodontic appliance generally influences greatly the clarity in the pronunciation of spirant consonant. This is in line with the opinion put that individuals with narrow palates generally experience distortion when pronouncing the / $\mathrm{s} /$ consonant. ${ }^{11}$

Just as patients who use removable orthodontic appliances both upper and lower jaw, this affects the dimensions of oral cavity and limit the movement of the tongue when speaking, causes distortion in many consonant pronunciations. Research conducted explains that patients who use maxillary and mandibular orthodontic appliances on the first day experience impaired speech articulation in consonant pronunciation / s / . ${ }^{12,13}$ Limitation of the results of this study is that there is no difference of research between active removable orthodontic appliances and passive removable orthodontic appliances. However there is no significant difference in the results obtained.

\section{CONCLUSION}

Speech articulation disorders in patients with orthodontic removable appliance varies with the presentation of having most articulation disorders is in the pronunciation of consonants /s/ in words.

\section{REFERENCES}

1. Judarwanto W. Proses Mekanisme Bicara Dan Bahasa : Proses Fisiologi Bicara. Wordpress. 2009.

2. Roth GI, Calmes R. Oral Biology. St.Louis: The C.V. Mosby Company. 1981. 85-86. pp

3. Snell RS. Anatomi Klinik Untuk Mahasiswa Kedokteran. Jakarta: Penerbit Buku Kedokteran EGC. 2006. 812. pp

4. Guyton AC, Hall JE. Fisiologi Kedokteran (Textbook of Medical Physiology). Jakarta: Penerbit Buku Kedokteran EGC. 2006;721, 756-8. pp

5. Haydar B, Karabulut G, Ozkan S, Aksoy SC. Effects of retainers on the articulation of speech. Americ J Ortho Dentofacial Orthopedics. 1996;110(5):535-539.

6. Isaacson KG, Muir JD, Reed RT. Removable Orthodontic Appliances. India: Elsevier. 2002. 1-5, 35-41, 102-6, 117-8. pp

7. Subhashchandra B. Orthodontics Principles and Practice. New Delhi: Jaypee Brothers Medical Publishers. 2011. 17-20. pp

8. Profitt WR, Fields HW. Contemporary Orthodontics. St. Louis, Missouri: Mosby. 2000. 363-384. pp

9. Samir E, Bishara. Textbook of Orthodontics. WB Saunders Company : Philadelphia. 2001. 566. pp

10. Kayikci ME, Akan S, Ciger S, Ozkan S. Effects of Hawley retainers on consonants and formant frequencies of vowels. Angle Orthodontist. 2012;82(1):14-21.

11. Laine T. Associations between articulatory disorders in speech and occlusal anomalies. Europ J Ort. 1987;9(1):144-150. DOI: https:// doi.org/10.1093/ejo/9.1.144

12. Haydar B, Karabulut G, Ozkan S, Aksoy SC. Effects of retainers on the articulation of speech. Americ J Ort Dentofac Orthoped. 1996;110(5),:535-539.

13. Kayikci M, Akan ES, Ciger S, Ozkan S. Effects of Hawley retainerson consonants and formant frequencies of vowels. Angle Orthodontist. 2012;82(1):14-21. 